\title{
Prototyping the Self-Authored Video Interview: Challenges and Opportunities
}

\author{
Stephen Snow ${ }^{(\bowtie)}$, Markus Rittenbruch, and Margot Brereton \\ Queensland University of Technology, 2 George Street, Brisbane, 4000, Australia \\ \{steve.snow, m.rittenbruch, m. brereton\} @qut.edu.au
}

\begin{abstract}
Self-authored video- where participants are in control of the creation of their own footage- is a means of creating innovative design material and including all members of a family in design activities. This paper describes our adaptation to this process called Self Authored Video Interviews (SAVIs) that we created and prototyped to better understand how families engage with situated technology in the home. We find the methodology produces unique insights into family dynamics in the home, uncovering assumptions and tensions unlikely to be discovered using more conventional methods. The paper outlines a number of challenges and opportunities associated with the methodology, specifically, maximising the value of the insights gathered by appealing to children to champion the cause, and how to counter perceptions of the lingering presence of researchers.
\end{abstract}

Keywords: Self-Authored video $\cdot$ Electricity $\cdot$ Eco-feedback $\cdot$ Family dynamics

\section{Introduction}

In this paper we discuss our experience prototyping a method we developed for investigating the use of situated technology in the home, called Self Authored Video Interviews (SAVIs). We developed the SAVI process as a means of encouraging all members of participating families to become involved in discussions around domestic energy consumption and their in-home energy use displays (eco-feedback systems). Methodologically, SAVIs are situated in between a form of design probe [8], qualitative interview, video diary [6] and the use of video as a design material more generally $[2,13]$. It resembles a design probe in that it is a temporary deployment of research technology in the home requiring creativity on the part of the recipient; a temporary imposition or disruption to domestic life. Yet we abstain from calling it a design probe in the truest sense [8], as it is more structured in the nature of interaction it promotes between the participant and the probe, sharing similarities with qualitative interviews. Despite this we found our initial SAVIs to reveal surprising and innovative perspectives and to be potentially useful as a design material. SAVIs also share similarities with video diaries [6] in that they encourage participants to document their personal opinions and feelings on video. They differ, however, in that SAVIs do not require regular updates or diary entries as per [6], whose participants created regular video diary entries with a laptop webcam. In contrast, SAVIs emphasise the participant as a film maker and creative 
director, utilising portable video cameras and a request that participants exercise their own artistic licence.

In the following paragraphs we document our experiences developing and prototyping the SAVI method, in particular its fit within the design space of energy consumption in the home. The concern of the paper is chiefly methodological and we do not discuss technical details of the energy consumption feedback system or the nature of its use by the families in great depth; these findings are reported elsewhere [11]. Rather, we document the experiences of our participants with the SAVIs and the characteristics of the methodology that led to the unique insights we gathered into families' energy consumption and the taken-for-granted assumptions made in this sphere. Also, we find that despite self-authored video being advocated as a means of reducing the intrusion of the researcher in the home [13], that some participants are still conscious of the researchers" "presence" as embodied in the camera itself. In light of these experiences, we make some suggestions for design and discuss some challenges and opportunities for how SAVIs might be modified to enhance the utility of participants and the quality of the data. These include: appealing to children to champion the SAVI cause rather than adults and ways of avoiding the perception among participants of the researchers owning the studied technology, or being embodied in (or on the other end of) the video cameras. We conclude by advocating SAVIs to be a useful means of encouraging participation from the whole family in discussions around energy consumption in the home and the design of technologies in this sphere.

\section{Background}

Video has long been identified as a strongly participatory media [9], where: "participation and emphatic engagement has to be invested to make sense of the material" [2, p. 1 citing 9] and has an established history of use as a design tool by HCI and participatory design practitioners $[2,3,13]$. In intimate settings such as the home environment, handing control over the creation of the video to the participants themselves has been advocated as a means of removing the intrusion of a researcher with a video camera [13]. Self-authored video provides a unique perspective through the family's eyes into what they deem to be important enough to video-tape, as opposed to what the researchers deem to be important, thus making visible the taken-for-granted assumptions of everyday life $[7,13]$. This sheds light on the idiosyncratic functioning of families and individuals [7] and provides insights derived from the moment, rather than from introspection.

In relation to energy use in the home, Pink et al. [10] used a video ethnography based approach as a means of exploring energy use in everyday life, and informing design concepts for energy saving interventions. This involved a process of "video tours" where: "One or more family members guided the ethnographer around their house... showing us how they make (or seek to make) the home 'feel right'” [10, pp. 25:6]. This was a means of exploring energy use indirectly. Bourgeois et al. [1] utilised a "technology probe" approach to gather information about the desires and needs of users when learning about the energy generated by their rooftop solar systems. The technology probe 
pack included video cameras to invite their participants to create their own self-authored videos. Interestingly, they note that none of their participants felt comfortable recording themselves on the cameras [1].

\subsection{Context and Rationale for SAVIs}

The particular context to which we chose to apply our SAVIs was the social context of domestic energy consumption in the home and eco-feedback [5, 12]. The intent was to acquire a broader participation of householders in discussions around their energy use and their eco-feedback systems, rather than hearing only from motivated lead-users. Despite the family-situatedness of eco-feedback, few studies employ a specific attempt to integrate all household members in the research simultaneously. Where this has been done, it has been found that while one family member may be knowledgeable and engaged with their eco-feedback system, other members of the same family may have no interest in it at all [5, 12]. As such, integrating all family members in these studies may paint a more accurate picture [12]. Our earlier work conducting individual interviews also led us to this conclusion; where the occasional chance participation in the interviews by other family members hinted at a far richer picture being available if participation could be extended to the whole family.

\section{SAVI Deployment Process}

The SAVI methodology was trialled with 12 families living in suburban South East Queensland in Australia. These 12 families had all received an eco-feedback system called 'Ecosphere' within the previous six months. The majority of the 12 families were married or de facto and all but three had children living at home. Nine self-authored videos were created in total; two families said they had been too busy and one did not feel comfortable recording themselves. Video cameras (Fig. 1) were deployed in the homes for a period of 1-2 weeks before being picked up.

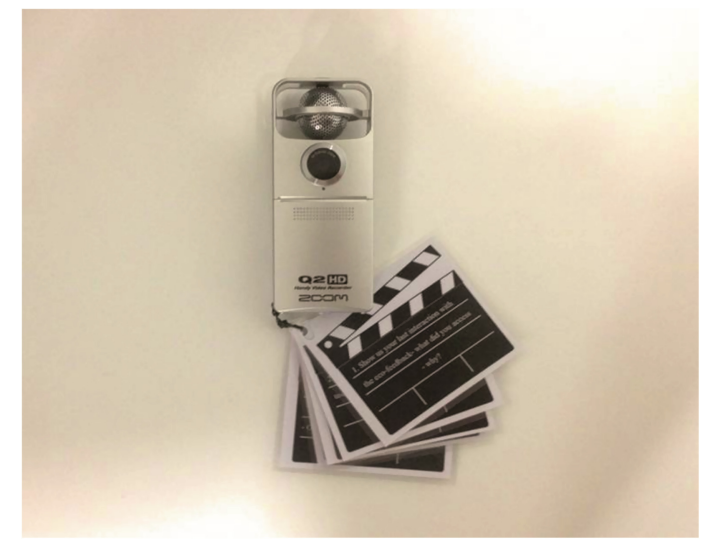

Fig. 1. The deployed video camera 
Attached to the cameras were a number of laminated cards (Fig. 1), with the questions: (1) Show us your last interaction with the eco-feedback (2) What features you do like- why? (3) What don't you like about it- why? (4) What has been happening recentlyi.e. hot weather, visitors, holidays etc. and (5) What have you learned from it, how did you learned it or who did you learn it from? The family member(s) home at the time of deployment was asked to request that all other family members answer the questions on camera individually. This format encouraged families to work together in the creation of video material. On the sixth flip-card was an optional invitation for the whole family to participate in the "Steven Spielberg Challenge". Here, each family was invited to make a short "mockumentary" about their energy use or eco-feedback. Suggestions for content included "outline the roles each family members plays in energy use in the household", "Design your own alternative eco-feedback system" and other similarly playful scenarios. This open-ended and creative exercise complemented the more structured nature of the first five flip cards. Unfortunately only three families completed the Steven Spielberg Challenges with others citing time constraints or unwillingness.

\subsection{Analysis}

Analysis of the SAVI data was a challenging process, on account of the SAVIs yielding data reminiscent in some ways of qualitative interviews from the first 5 flip cards and much more playful, ambiguous and less structured content from the "Steven Spielberg Challenge". While we wished to analyse responses from the first five questions, we did not wish to impose order on what was at times highly ambiguous and creative data. Analysis initially took the form of preparing "video cards", as per the initial steps of [3]. Several stills from each family's videos were printed onto A4 sheets with the researchers adding annotations and quotes that were spoken at the time of the still. The creation of cards in this manner represented a useful means of capturing points of interest in the audio and video data. Separately, all audio from the videos was transcribed. A thematic analysis process was then undertaken utilising both quotes from the audio alone as well as the pre-prepared video cards. During this process many more video cards were created in order to capture moments, facial expressions and nuances of interactions that were representative of the different themes that emerged during the analysis.

\section{Overview of Findings}

While SAVIs were useful in the practical sense of their role as an alternative for group interviews, the depth of the findings extended far beyond that possible with interviews alone. The process provided a unique and rich insight into the families' conceptualisation of energy, the use of their eco-feedback and the taken-for-granted assumptions made by people in relation to their energy use. This was key to our becoming aware of the elements of control, responsibility, power and play that occur within families in relation to their energy use. These findings are reported elsewhere in detail [11] and in this section we concentrate instead on sharing some of the issues we found concerning the SAVI methodology and participation. 


\subsection{Taken-for-Granted Assumptions}

Ylirisku \& Buur [13] note how self-authored video can shed light on taken-for-granted assumptions that would not become evident with interviews alone. We found several examples of this, which provided considerable insight into family dynamics around ecofeedback. The 13 year old daughter of Family 6 for instance unwittingly referred to electricity in the house as belonging to her dad and identified the eco-feedback as something that was there to save it. She was empathetic to her father's energy saving cause, calling out other family members if she considered them to be wasteful. One example of this was demonstrated in the family's Steven Spielberg Challenge, involving the 13 year old daughter pushing her similar-aged relative into the swimming pool as retribution for getting her in trouble over the air conditioning:
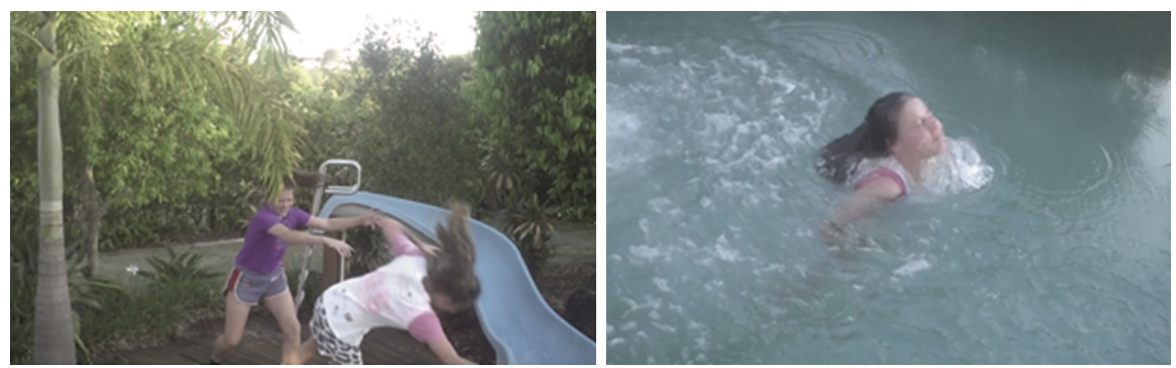

Girl 1: "For god's sake! You've been in bed with the air conditioning on and dad's blamed me! You're horrible! Girl 2: [screams]."

The two teenage boys from Family 9 made a short film for their Steven Spielberg Challenge. This film parodied the human power relations of saving energy in the home and the lead-user of the eco-feedback getting a little too obsessed with his "Spherey"a nickname for the Ecosphere eco-feedback system. This involved one son dressed up in an apron and spectacles, menacing his co-inhabitants with a spatula.
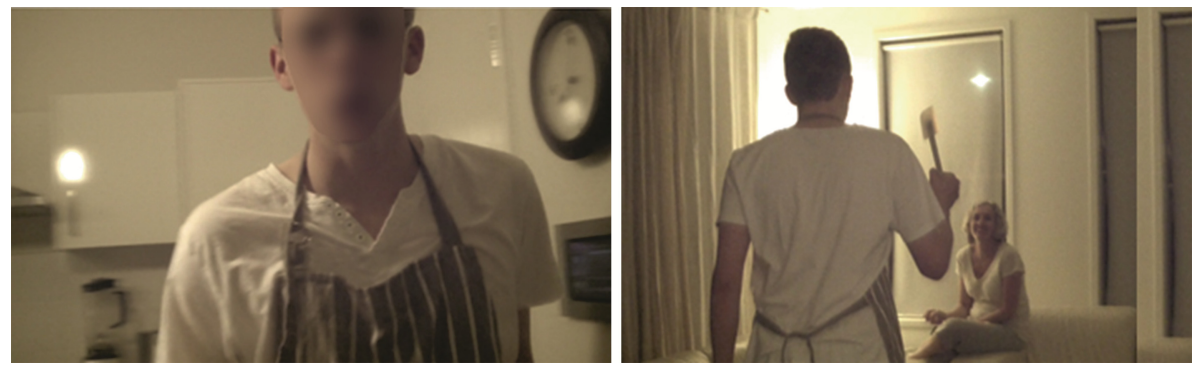

Son: [looks at the eco-feedback, turns to mother] You were using the heat lamp!

Mother: I might have been... 
Son: I don't care. That's 10 lashings for you! You know what? I've had it! Me and Spherey need some time alone!

What is interesting here is that in the pre-install interview, their mother spoke of the boys generally being very good with electricity use and of her not needing to police it. Furthermore, there was at present no father figure in the household, the boys living with their mother who had separated from their father. Thus it appeared the boys were acting out a (humorously dramatised) representation not of what happened in their home, but of what they thought might have been the case in other homes.

\subsection{Factors Affecting Data Quality}

In relation to the quality of data produced by the SAVIs, we found the most informative and comprehensive content came from instances where (1) one family member championed the cause of the SAVI and (2) when the family did not see the camera as an embodiment of us as researchers.

The Champions: The 13 year old daughter of Family 6 made the camera her own and took it upon herself to interview not only everyone in her family, but some of her relatives who were visiting from England. This sometimes involved protests from her subjects if they were caught unawares or put on the spot. The championing of the SAVI activity by this girl provided excellent data on the range of opinions and conceptualisations of the eco-feedback by different family members that we may not have been privy to without her insistence. In Family 4, the wife championed the SAVIs and interviewed her somewhat reluctant husband and teenage children, probing them further if she received an inadequate answer. This led to an insight into the family dynamics in relation to the eco-feedback, where it transpired the wife was in fact the only one who ever used it; her husband admitting: "It just looks a good bit of kit. I don't really know how to use $i t$ ” (Husband, Family 4).

The Lingering Presence of the Researcher: A key distinction we found in the data was the degree to which different creators of SAVI material conceptualised the camera as an embodiment of us as researchers. The children from Family 6 and Family 9 displayed no intention to cater for the audience of their videos and appeared to derive a lot of fun from creating imaginative, humorous and (for us) very insightful material. Some participants from other families however, particularly adults, appeared much more conscious of the fact that they were providing material that would be watched by us researchers. This was particularly so in Family 2 and Family 7, where some responses appeared cautious and measured. For example, both the wife and adult daughter of Family 7 both began by formally introducing themselves: "Hello my name is [S] and I am the daughter of [D] and [L] from [house number and street address]"- Daughter, 21 , Family 7 . The careful wording and staccato delivery of a response by a 10 year old daughter from Family 2 caused us to wonder whether she may have been instructed by her parents to make sure she said what they thought was appropriate to say, rather than what she thought herself: "We have learned from the eco-system that rather than using our air con, we have to use the fans and that if we're not using the lights, we have to 
make sure that they're turned off'- Daughter, 10 Family 2. While this was interesting in its own right, it was the responses from participants who were not self-conscious or concerned about their potential audience which provided the most insight into energy consumption and eco-feedback in the home.

\section{Opportunities and Challenges for Future SAVI Deployments}

Above we have highlighted the creative and insightful data obtained by encouraging participation from the whole household in matters of domestic energy consumption through the use of SAVIs. The more structured question cards provided data reminiscent of a qualitative interview, whereas the Steven Spielberg Challenge provided more creative, unexpected and insightful glimpses into family relations around domestic energy use. Based on these examples above, we conclude with reflections on how SAVI's may be improved in subsequent iterations as well as future opportunities for the methodology.

One of the advantages of self-authored video is the ability to gather insights into the function of a family home without the intrusion of a researcher holding a camera [13]. Yet we still found some participants speaking to the camera as if we were in fact still in their home- behind the camera. One challenge we see for future SAVIs is how to transcend this notion. Although we did not design the Ecosphere ourselves, we wonder whether some participants may have thought we did, on account of us conducting the pre-install interviews at the same time as the installers were conducting their own preinstall assessments. We believe that the researchers' disconnection to the device in question is important and that future deployments of SAVIs should be carried out by researchers who are seen to be completely disconnected to the design and install of the technology in question. This might include a different researcher deploying the SAVIs who introduces themselves as independent from the technology.

Another possibility for this is a more specific integration of children in the SAVI's. Despite deploying the SAVIs to adult members of the households, children were vital to the success of our SAVI deployment and were responsible for the creation of some of the most insightful material of the whole exercise. We believe one means of improving the SAVI process is extending the scope of the creative component and, where possible, specifically assigning responsibility for the SAVIs to children, inviting them to take leading roles both behind and in front of the camera. Putting children in specific control of the exercise in this way, and later reporting the content generated, would require that careful consideration be paid to ethical issues such as parental supervision and informed consent for those depicted in the videos. Despite this, we feel placing children more in charge of SAVI deployments would be useful both in generating more insightful SAVI data and countering the noticeable absence of children from HCI explorations of ecofeedback in the home more generally.

As a final reflection, while we advocate the SAVI methodology of combining structure (interview questions) with creativity (Steven Spielberg Challenge), we appeal to future practitioners of this method to pay attention to the analysis of the resultant data. This was a source of tension for us, deploying what can be interpreted as a form of a design probe, but using it to ask five questions of our participants more reminiscent of 
a qualitative interview. We are aware of Gaver and colleagues' [4] lament over the tendency (at the time) for authors to analyse, rationalise, and even produce design requirements from probe results- quite at odds with the original ludic and inspirational intent of the original method. Although we do not identify the SAVI's as probes and feel the attachment of interview style questions to the cameras was very successful, we are aware that as a methodology, SAVIs may still sail rather close to this wind. As such, for future SAVI adaptations, while we feel it is still necessary to impose some sort of order, at least on the interview components, we implore fellow authors not to consider the creative components as "hard data" [2] or as evidence on which to base requirements for design. Instead, that attention is paid in the analysis process to attempting to understand the world through the eyes of the different family members and use this as a tool for ideation and design inspiration.

In closing, we advocate SAVIs as a useful means of gathering rich data on how families orient towards energy consumption and eco-feedback and how eco-feedback itself shapes family relations. In this paper we have outlined our particular deployment, some of the challenges we faced and some of the opportunities we see for future deployments. We hope other authors will adapt and improve upon this methodology and share their experiences of doing so.

\section{References}

1. Bourgeois, J., van der Linden, J., Price, B., Kortuem, G.: Technology probes: experiences with home energy feedback. In: Methods for Studying Technology in the Home: Workshop paper, CHI 2013, Paris, France (2013)

2. Buur, J., Binder, T., Brandt, E.: Taking video beyond 'hard data' in user centred design. In: Proceedings of the Participatory Design Conference, New York, pp. 21-29 (2000)

3. Buur, J., Soendergaard, A.: Video card game: an augmented environment for user centred design discussions. In: Proceedings of the Designing Augmented Reality Environments, pp. 63-69. ACM Press (2000)

4. Gaver, W., Boucher, A., Pennington, S., Walker, B.: Cultural Probes and the value of uncertainty. Interactions XI(5), 53-56 (2004)

5. Hargreaves, T., Nye, M., Burgess, J.: Keeping energy visible: Exploring how householders interact with feedback from smart energy monitors in the longer term. Energy Policy 52, 126134 (2013)

6. Iivari, N., Kinnula, M., Kuure, L., Molin-Juustila, T.: Video diary as a means for data gathering with children- Encountering identities in the making. Int. J. Hum.-Comput. Stud. 72, 507-521 (2014)

7. Jacknis, I.: Margaret mead and gregory Bateson in Bali: Their use of photography and film. Cult. Anthropol. 3, 160-177 (1988)

8. Mattelmäki, T.: Design Probes. University of Art and Design Helsinki. Gummerus Printing, Vaajakoski (2006)

9. McLuhan, M.: Understanding Media: The Extensions of Man. MIT Press, Cambridge (1964)

10. Pink, S., Mackley, K.L., Mitchell, V., Hanratty, M., Escobar-Tello, C., Bhamra, T., Morosanu, R.: Applying the lens of sensory ethnography to sustainable HCI. ACM Trans. Comput. Hum. Interact. 20(4), 1-8 (2013). Article 25

11. Snow, S., Vyas, D., Brereton, M.: When an eco-feedback system joins the family. J. Pers. Ubiquitous Comput. Published online 10th February 2015 (2015) 
12. Strengers, Y.: Smart Technologies in Everyday Life: Smart Utopia?. Palgrave McMillan, London (2013)

13. Ylirisku, S., Buur, J.: Designing with Video. Focusing the User-Centred Design Process. Springer Press, London (2007) 